\title{
An Assessment of Contaminants in UK Road-Verge Biomass and the Implications for Use as Anaerobic Digestion Feedstock
}

\author{
Patrick E. Mason ${ }^{1}$ - $\cdot$ Luke Higgins $^{1} \cdot$ Fernando Climent Barba ${ }^{1} \cdot$ Adrian Cunliffe $^{1} \cdot$ Nick Cheffins $^{2}$. \\ Douglas Robinson ${ }^{3}$. Jenny M. Jones ${ }^{1}$
}

Received: 3 November 2018 / Accepted: 17 December 2018 / Published online: 27 December 2018

(c) The Author(s) 2018

\begin{abstract}
Biomass from harvested road-verge herbage has potential value as a feedstock for anaerobic digestion (AD) energy plants. However, the proximity to road traffic related pollution sources introduces the possibility of contamination by potentially toxic elements and polycyclic aromatic hydrocarbons. Potential sources of pollution from road traffic emissions are identified and the consequent likelihood of certain contaminants being present at elevated levels is assessed. Samples of road verge biomass harvested from selected locations in Lincolnshire UK for use in AD plants were analysed to produce a set of measurements for the presence of the contaminants of interest. The measured levels of these contaminants are compared to reported background levels in UK herbage and soils to assess if there is significant increased concentration in road-verge biomass. Samples of digestate from an AD plant using the road-verge biomass as feedstock were also analysed to determine if there is notable risk of transfer and concentration of contaminants into agricultural land where the digestate may be used for fertilisation. While elevated levels of contaminants were detected, they were not found in concentrations on road verge biomass at high enough levels to cause adverse effects or concerns for its safe use as an AD feedstock.
\end{abstract}

Keywords Biomass feedstocks $\cdot$ Anaerobic digestion $\cdot$ Road verge $\cdot$ Potentially toxic elements $\cdot$ Polycyclic aromatic hydrocarbons

\section{Statement of Novelty}

This study was conducted as part of a wider investigation undertaken by Lincolnshire County Council for evaluation of potential harvesting road verge biomass. This included technological and economic analyses. The associated investigation described here was undertaken to assess the likely levels of key contaminants in the road verge biomass and possible risks associated with its use in anaerobic digestion (AD). The overall study was itself the first of its kind in terms of scale and scope. The data produced and presented in this article answers specific concerns about the viability

Patrick E. Mason

p.e.mason@leeds.ac.uk

1 School of Chemical and Process Engineering, University of Leeds, LS2 9JT Leeds, UK

2 Peakhill Associates, Welton, LN2 3LH Lincoln, UK

3 Linconshire County Council, County Offices, Newland, LN1 1NY Lincoln, UK of the use of road verge biomass. The detail of the analysis are previously unpublished and are very useful reference for similar future projects.

\section{Introduction}

\section{Anaerobic Digestion}

A major advantage of AD as an energy conversion technology is the ability to use diverse feedstocks including sewage, food waste, industrial by-products (such as brewer's grains), residues from agricultural cultivation, conservation and land management as well as dedicated energy crops. Many of these feedstocks cannot be effectively used in other energy conversion systems while $\mathrm{AD}$ can also produce a digestate residue which can be utilised for agricultural fertiliser. Furthermore, the primary product, biogas, can be used for electricity generation (either locally or to grid), heat production or it can even be upgraded to high grade biomethane for injection into the national gas grid. Nevertheless, it is not 
necessarily economically attractive to businesses and farms to invest in $\mathrm{AD}$ without some certainty in the supply chains of low-cost feedstocks and in the price received for electricity, heat and biomethane. In the UK, as a result of policies to reduce carbon emissions and manage waste streams, the technology has been supported through renewable energy subsidy mechanisms including feed-in-tariffs and the renewable heat incentive [1]. AD applications cover a range of scales, a wide range of potential feedstock inputs and a range of product outputs. This has produced an interplay between food, water and energy sectors allowing optimisation of the sustainability of each [2]. The flexibility and sector crosscutting aspects of $\mathrm{AD}$ have then allowed innovative applications and uses for materials as feedstocks where previously there were no economical or environmentally sustainable use for them. A good example of this is the potential use of herbage cuttings from the maintenance of green spaces such as road-verges by local authorities.

\section{Road Verge Biomass for AD Feedstock}

The potential for use of non-agricultural green 'waste' from municipal green spaces was investigated in Germany by Pick et al. [3]. This concluded that there is large potential for utilisation of such materials as feedstocks from biogas production but technical, legal and economic factors precluded the vast majority of biomass from being used. Studies into the feasibility of using road verge biomass specifically include the study by Meyer et al. in Denmark [4] and and by Piepenschneider et al. in Kassel, Germany [5]. The Meyer study included an estimate that such a resource could account of up to $3 \%$ of Danish biogas production. The energy return on energy invested (the ratio of useful energy produced to the total energy used by the process) was estimated to be marginal (between 2 and 3) but with additional associated benefits accounted for, the practice can be considered economically viable. The additional benefits include the use of the digestate for fertiliser and soil improver [6, 7]. Furthermore, other studies have shown that removal of cuttings from verges can enhance biodiversity and ecological richness [8].

\section{Road Verge Biomass in UK}

AD plants have become increasingly common in the UK over the past decade with numbers of operational plants growing from around 30 in 2008 to over 600 in 2018 . The majority of these plants are installed in rural areas and more than half on farms $[9,10]$.

There are nearly $400,000 \mathrm{~km}$ of roads in the UK, much of which are bordered by grass verges [11]. In certain areas, vegetation growth on road verges are managed by regular mowing for reasons of safety (driver visibility), road maintenance and aesthetics. The cuttings from verge mowing are generally left to decompose or form mulch but, as established in previous studies, they can also be considered as a potential source of $\mathrm{AD}$ feedstock. Lincolnshire County Council, having responsibility for over $8750 \mathrm{~km}$ of mainly rural roads with grass verges, commissioned a feasibility study in 2015 on the use of road-verge biomass for use as an AD feedstock as a long-term practice. The resulting study [12] concluded that such proposals were feasible but would require innovative approaches and further evaluation including:

- Investigation on improved efficient and cost-effective means of harvesting and delivering to local AD operators;

- Field trials to assess actual harvest yields and biomethane potential;

- Analysis to establish the levels of contaminants in the harvested biomass.

The latter of these is the subject of this article and is thus effectively a continuation of the study undertaken for Lincolnshire County Council. The other aspects of the evaluation have been undertaken in a related work-package and reported in a separate study [13].

\section{Potentially Toxic Elements (PTEs)}

PTEs are a group of metals and metalloids that are known to be toxic to human and plant health if delivered in high doses. These elements are commonly called "heavy metals" but to be more precise, we refer to them here as PTEs [14].

In the context of $\mathrm{AD}$, high concentrations of PTEs can adversely affect key biochemical processes. By binding to or displacing other metals from various biomolecules, PTEs can disrupt enzyme functions. In turn, this can inhibit both acidogenic and methanogenic microorganisms thus reducing the efficacy of biogas production [15]. While PTEs present more of a risk from feedstocks derived from sewage, they may also bioaccumulate in other feedstocks including grasses [16]. As a result, PTE toxicity is one of the main factors in reduced performance or failure of anaerobic digestors [15]. It is therefore important for AD operators to monitor and minimise levels of PTEs in their process water in order to sustain the effectiveness of the digestion process.

Additionally, operators must maintain acceptable levels of PTEs in their digestate. In the UK, the Environment Agency places strict legislative limits on the concentrations of PTEs that may be released into the environment through the use of digestate as fertiliser-as this could lead to the biomagnification of PTEs in the soil. An operator would have to pay significant disposal costs if their digestate did not meet the regulatory standards. In the UK, the key pieces 
of environmental legislation that applies to PTEs in products from $\mathrm{AD}$ are:

- Environmental Permitting Regulations (EPR) - For an AD plant to operate it must hold environmental permits for the digestion of waste, use of a digester, the storage of digestate, biogas combustion and further permits for transport and other uses. The EPR legislation came into effect on 6th April 2010 and covers a wide range of industry and processes.

- End of Waste Criteria (EoW) - End of Waste criteria is composed of the Digestion Quality Protocol [17] and the applied publicly available specification PAS-110 [18]. These documents set out a framework for what type of biowaste can be digested, best practice and levels of contaminants in digestate-including PTEs. Once the EoW criteria have been met, the digestate and biogas are no longer classed as waste and can be used without obtaining an environmental permit.

A further consideration for $\mathrm{AD}$ operators to be aware of is the effect that some PTEs have as micronutrients and are required in low concentrations to maintain the complex biochemistry that occurs in $\mathrm{AD}$ plants. Although some $(\mathrm{Cd}, \mathrm{Pb}$, $\mathrm{Hg}$ ) seem to offer nothing to bacterial processes, micronutrients such as zinc and manganese, stimulate biochemical processes that are vital for the production of biogas. In some cases, operators may add some of these elements to the feedstock to stimulate the AD process [19].

Sources of PTEs from traffic related emissions are likely to contribute to the contamination of road-verge biomass. The three main sources of PTE emissions from road vehicles are: (i) combustion engine exhaust; (ii) Particles from tyre wear; (iii) particles from brake wear. In addition to this, particles from the road surface itself may contain PTE and PAH contaminant, particularly if the surfacing contains bitumen. Studies on the concentrations of PTEs from these sources are referenced to provide an indication of which are likely to be present in elevated levels [20,21].

PTEs present in the wider environment of the UK were surveyed in 2007 by the Environment Agency [22]. The average levels reported in soils and on herbage from that survey can be used as references to assess if measured levels in feedstocks are unusually high. Published studies on the levels of PTEs in road dust can also be used as references for context and comparison with measured results [23, 24].

Table 1 presents data from published literature indicating the relative concentrations of the most prevalent PTEs as measured in various sources and in the road environment together with the PAS 110 limits where applicable.

\section{Polycyclic Aromatic Hydrocarbons (PAHs)}

Polycyclic aromatic hydrocarbons (PAHs) are a group of hundreds of compounds formed of multi-fused aromatic rings. They generally have high boiling points and low vapour pressures and are therefore solid in standard conditions. They are non-polar so tend to have very low aqueous solubility although they are also lipophilic so tend to be very soluble in organic solvents.

PAH compounds are ubiquitous and persist throughout the environment in soil, air and water, many having a halflife of 2 years. High concentrations are a concern owing to their potential to be harmful to organisms and human health. Exposure can be by ingestion from contamination of food or by inhalation of PAH particulates (from smoke for

Table 1 PTE contamination: traffic related sources; levels measured in environment; PAS 110 limits

\begin{tabular}{|c|c|c|c|c|c|c|c|}
\hline \multirow[t]{3}{*}{ PTE } & \multicolumn{3}{|c|}{ Traffic related pollution sources } & \multicolumn{3}{|c|}{ Levels measured in environment } & \multirow{2}{*}{$\begin{array}{l}\text { PAS } 110 \\
\text { Limit in digestate }\end{array}$} \\
\hline & Brake wear particles & Tyre wear particles & $\begin{array}{l}\text { Transport } \\
\text { fuel emis- } \\
\text { sions }\end{array}$ & Road dust & $\begin{array}{l}\text { UK rural } \\
\text { soil average }\end{array}$ & $\begin{array}{l}\text { UK rural } \\
\text { herbage aver- } \\
\text { age }\end{array}$ & \\
\hline & $\mu \mathrm{g} / \mathrm{g}$ & $\mu \mathrm{g} / \mathrm{g}$ & $\mu \mathrm{g} / \mathrm{kg}$ & $\mu \mathrm{g} / \mathrm{g}$ & $\mu \mathrm{g} / \mathrm{g}$ & $\mu \mathrm{g} / \mathrm{g}$ & $\mu \mathrm{g} / \mathrm{g}$ \\
\hline Arsenic (As) & $<2-11$ & - & $0.26-0.34$ & - & 10.9 & 0.56 & - \\
\hline Manganese (Mn) & $62-5640$ & $0.8-2.5$ & - & 486 & 612 & 243 & - \\
\hline Nickel (Ni) & $80-730$ & $<1-3$ & $0.79-1.1$ & - & 21.1 & 1.76 & 50 \\
\hline Copper $(\mathrm{Cu})$ & $70-39 \mathrm{k}$ & $<2-3$ & $3.4-8.7$ & $75-87$ & 20.6 & 7.26 & 200 \\
\hline Zinc $(\mathrm{Zn})$ & $120-27 \mathrm{k}$ & $5650-9640$ & $16-44$ & $122-175$ & 81.3 & 35.90 & 400 \\
\hline Selenium (Se) & $4.5-115$ & - & $0.18-0.2$ & - & - & - & - \\
\hline Cadmium (Cd) & $<0.1-2.6$ & $<0.05-0.34$ & $0.24-0.34$ & 1.4 & 0.39 & 0.14 & 1.5 \\
\hline Lead $(\mathrm{Pb})$ & 4-1290 & $1-5.7$ & $1.3-1.8$ & $39-233$ & 52.6 & 2.12 & 200 \\
\hline Mercury (Hg) & $<0.1-0.3$ & $<0.01-0.03$ & $2.3-9.2$ & - & 0.13 & 0.07 & 1.0 \\
\hline Chromium (Cr) & $135-1320$ & $<1-2$ & $5.6-13$ & 56 & 34.4 & 1.76 & 100 \\
\hline Source reference & {$[20,25]$} & {$[20,25]$} & {$[21]$} & {$[23,24]$} & {$[22]$} & {$[22]$} & {$[18]$} \\
\hline
\end{tabular}


example). In humans, they can cause adverse health effects such as depressed immune function, internal organ damage and pulmonary disease as well as being carcinogenic [26].

In the $\mathrm{AD}$ process, PAHs can be concentrated in the digestate so use of this as fertilizer risks increasing PAH concentration in agricultural soils and bioaccumulation in crops [27]. This is clearly undesirable where food crops are cultivated owing to the health risks of PAH ingestion described previously.

Sources of PAH contamination include pyrogenic processes (from pyrolysis or incomplete combustion of organic fuels), petrogenic (from crude oil or coal) or biological (from degradation of vegetation) [26]. In the context of road verge contamination, the sources of PAH contamination that are likely to contribute to elevated levels are from road vehicles. The three main sources of PAH emissions from road vehicles are the same as with PTEs: (i) combustion engine exhaust; (ii) Particles from tyre wear; (iii) particles from brake wear.

Particles formed of or containing PAH compounds can be deposited on herbage directly as dry particulate precipitation. Rainfall may also contain PAH from the atmosphere which is then deposited on leaves. However, rainfall will also wash extraneous material off herbage and into the soil. Concentrations of PAH in soils are therefore likely to be much higher than those on the herbage itself.
The presence of PAH in the wider environment of the UK were surveyed in 2007 by the Environment Agency [28]. The average levels reported in soils and on herbage from that survey can be used as references to assess if measured levels in feedstocks are unusually high.

The United States Environmental Protection Agency (US EPA) established a list of 16 priority PAHs based on their high levels of toxicity and concentrations in the environment as well as standardised methods for analysis of PAHs in environmental samples [29]. The 16 'priority PAHs' are listed in Table 2 with data from literature indicating the relative concentrations of PAHs as measured in various sources and in the road environment.

The environmental legislation that applies to PTEs in products from $\mathrm{AD}$ do not cover PAH contamination. However, the use of $\mathrm{AD}$ digestate as a soil improver/fertiliser is comparable to similar use of sewage sludge for which there is a proposed EU limit of $6 \mathrm{mg} / \mathrm{kg}$ [33].

\section{Scope of Study}

This study addresses one of the issues identified in the feasibility study on use of road-verge biomass for $\mathrm{AD}$ prepared for Lincolnshire County Council [12], namely: to establish the levels of contaminants in the harvested biomass. From a review of key pollutants associated

Table 2 PAH contamination: traffic related sources and levels measured in environment

\begin{tabular}{|c|c|c|c|c|c|c|}
\hline \multirow[t]{3}{*}{$\mathrm{PAH}$} & \multicolumn{3}{|c|}{ Traffic related pollution sources } & \multicolumn{3}{|c|}{ Levels measured in environment } \\
\hline & $\begin{array}{l}\text { Brake wear } \\
\text { particles }\end{array}$ & Tyre wear particles & $\begin{array}{l}\text { Diesel fuel } \\
\text { emissions }\end{array}$ & Road dust & $\begin{array}{l}\text { UK rural soil } \\
\text { average }\end{array}$ & $\begin{array}{l}\text { UK rural } \\
\text { herbage } \\
\text { average }\end{array}$ \\
\hline & $\mu \mathrm{g} / \mathrm{g}$ & $\mu \mathrm{g} / \mathrm{g}$ & $\mu \mathrm{g} / \mathrm{g}$ & $\mu \mathrm{g} / \mathrm{g}$ & $\mu \mathrm{g} / \mathrm{g}$ & $\mu \mathrm{g} / \mathrm{g}$ \\
\hline Napthalene & & & 1.83 & & & \\
\hline Acenaphthylene & & $8.2-20$ & 0.46 & & 0.03 & 0.030 \\
\hline Acenaphthene & & & 0.26 & & 0.01 & 0.010 \\
\hline Fluorene & & & 0.41 & & 0.12 & 0.013 \\
\hline Phenanthrene & 0.97 & $6.2-18$ & 0.54 & 3.9 & 0.13 & 0.047 \\
\hline Anthracene & & $0-1.6$ & 0.21 & 0.84 & 0.12 & 0.011 \\
\hline Flouranthene & 0.69 & $9.4-29$ & 0.31 & 6.9 & 0.23 & 0.017 \\
\hline Pyrene & 1.1 & $11-70$ & 0.30 & 9.4 & 0.19 & 0.015 \\
\hline Benz(a)anthracene & 1.5 & $0-3.8$ & 0.21 & & 0.12 & 0.007 \\
\hline Chrysene & 1.7 & $8.2-14$ & 0.21 & & 0.15 & 0.011 \\
\hline Benzo(b)fluoranthene & 0.42 & & 0.15 & & 0.22 & 0.012 \\
\hline Benzo(k)fluoranthene & 0.62 & & 0.18 & & 0.09 & 0.013 \\
\hline Benzo(a)pyrene & 0.74 & $3.9-6.4$ & 0.18 & & 0.22 & 0.009 \\
\hline Indeno(1,2,3,cd)pyrene & 2.6 & & 0.03 & & 0.14 & 0.007 \\
\hline Dibenzo(a,h)anthracene & & & 0.03 & & 0.032 & 0.005 \\
\hline $\operatorname{Benzo}(\mathrm{g}, \mathrm{h}, \mathrm{i})$ perylene & 0.34 & $0-34$ & 0.62 & & 0.12 & 0.011 \\
\hline$\sum 16 \mathrm{PAH}$ & & & & & 1.92 & 0.22 \\
\hline Source reference & {$[30,31]$} & {$[31]$} & {$[32]$} & [31] & [28] & [28] \\
\hline
\end{tabular}


with road vehicles, a selection of PTEs and PAHs have been identified as contaminants likely to be in elevated concentrations in road-verge biomass. The concentrations of these contaminants in samples from road-verge biomass harvesting trails in Lincolnshire are evaluated in this study. This allows assessment to establish if the observed levels are significantly higher than background levels. In addition, samples of digestate resulting from use of the road-verge biomass in AD are analysed to assess the levels of the same contaminants. While this covers a limited geographical and temporal scope, evidence regarding the risks associated with feedstock contamination is provided and the study provides a useful body of data on this subject.

\section{Methodology}

\section{Harvesting Sites and Sampling}

Trials for harvesting road verge biomass for evaluating the feasibility of its use in AD were undertaken by Lincolnshire County Council in 2016. Fig. 1 shows the location of the sites chosen for these trails with further details provided in Table 3. The sites vary from main trunk-roads (UK ' $A$ ' roads) and smaller rural lanes.

The sample designations are given by a reference in the form Sx.Hy.z where: Sx indicates the site reference:where $\mathrm{x}=1,2,6,9,10,11$ as listed in Table 3 and shown on map in Fig. 1.

Hy.z indicates the harvesting reference:There may be 2 or more harvests in a season: $y=1$ indicates first harvest

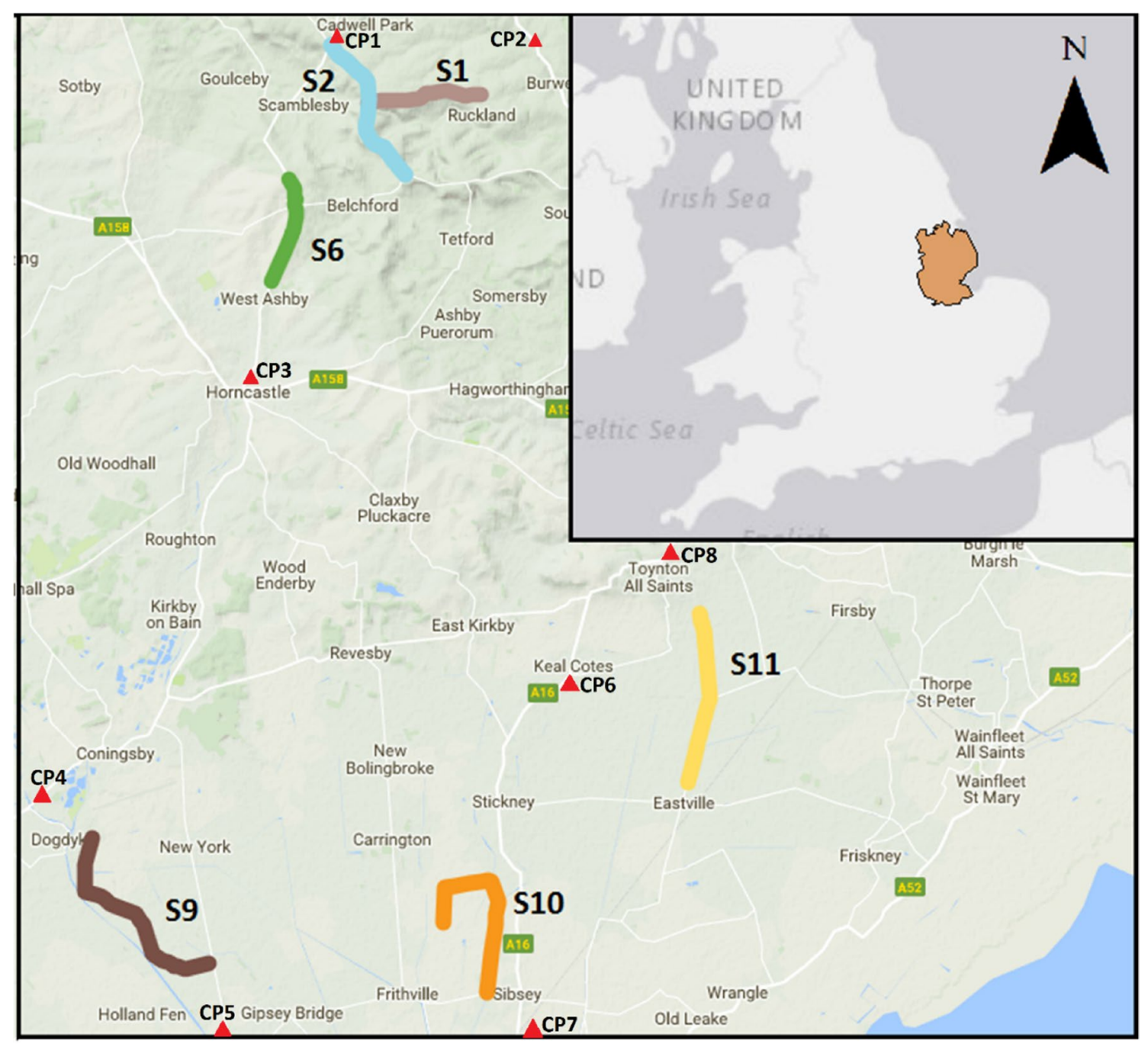

Fig. 1 Map of part of Lincolnshire in eastern England showing the sites (S1/S2/S6/S9/S10/S11) of road verge biomass harvesting for AD trials in 2016 (filled triangle indicates traffic count point) 
Table 3 Sampling site details

\begin{tabular}{|c|c|c|c|c|c|c|}
\hline Site & Road & $\begin{array}{l}\text { Nearest main } \\
\operatorname{road}(\mathrm{s})\end{array}$ & $\begin{array}{l}\text { Distance to nearest } \\
\text { main road }(\mathrm{km})\end{array}$ & $\begin{array}{l}\text { Distance to nearest } \\
\text { count point }(\mathrm{km})\end{array}$ & $\begin{array}{l}\text { Average daily } \\
\text { traffic count }^{\mathrm{a}}\end{array}$ & $\begin{array}{l}\text { Traffic count point } \\
\text { reference (see } \\
\text { Fig. 1) }\end{array}$ \\
\hline \multirow[t]{2}{*}{$\mathrm{S} 1$} & \multirow[t]{2}{*}{ Oslear's lane (unclassified) } & A153 & 3 & 3 & 3583 & $\mathrm{CP} 1$ \\
\hline & & A16 & 1 & 4 & 8316 & $\mathrm{CP} 2$ \\
\hline \multirow[t]{2}{*}{$\mathrm{S} 2$} & \multirow[t]{2}{*}{ Bluestone heath road (A1028) } & A153 & 1 & 1 & 3583 & $\mathrm{CP} 1$ \\
\hline & & A16 & 6 & 6 & 8316 & $\mathrm{CP} 2$ \\
\hline \multirow[t]{2}{*}{ S6 } & \multirow[t]{2}{*}{ Foxendale hill (A153) } & A153 & 0 & 4 & 3583 & $\mathrm{CP} 1$ \\
\hline & & A153 & 0 & 5 & 10,547 & $\mathrm{CP} 3$ \\
\hline \multirow[t]{2}{*}{ S9 } & \multirow[t]{2}{*}{ Hurnbridge lane (unclassified) } & A153 & 3 & 3 & 8405 & $\mathrm{CP} 4$ \\
\hline & & A1121 & 7 & 7 & 7535 & CP5 \\
\hline \multirow[t]{2}{*}{ S10 } & \multirow[t]{2}{*}{ Trader bank lane (unclassified) } & A16 & 1 & 9 & 6198 & CP6 \\
\hline & & A16 & 1 & 6 & 21,219 & $\mathrm{CP} 7$ \\
\hline \multirow[t]{2}{*}{$\mathrm{S} 11$} & \multirow[t]{2}{*}{ Spilsby road (unclassified) } & A16 & 3 & 5 & 6198 & CP6 \\
\hline & & A16 & 3 & 3 & 10,712 & CP8 \\
\hline
\end{tabular}

${ }^{\mathrm{a}}$ Data for all motor vehicles from nearest monitoring points—average daily traffic flow 2014-2016 [34]

of season. In some cases, the cutting machinery may be required to run along the verge twice to cover a wider width or higher growth of verge during the same harvest. $z=1$ indicates the first swath of cutting during the harvest; $z=2$ indicates a second swath of cutting on same stretch of road.

In addition to the road-verge biomass samples, other samples were obtained of feedstocks currently used in an on-farm AD plant at Scrivelsby, located near to the sampling sites. These feedstocks were taken from farm storage systems (vertical-wall concrete storage clamps) and included maize, rye grass and grass silage. Samples of digestate resulting from $\mathrm{AD}$ with the road-verge biomass were also collected from this AD plant. Details of the AD plant of this site can be found in a public database of operational AD plants [35].

Samples (1-2 kg) were taken from the mixed bulk material on site and transported in air-tight containers to the lab where they were then stored at $-20^{\circ} \mathrm{C}$ prior to the analysis. Sub-samples for analysis were obtained by coning and quartering (in accordance with ISO 14,780). Moisture content of the 'as-received' samples was measured (in accordance with ISO 18134-3:2015). The measured moisture content of each feedstock was as follows: road-verge biomass $76 \%$; rye grass $84 \%$; maize $53 \%$; grass silage $73 \%$.

\section{PTE Analysis}

The samples were initially reduced to $<100 \mu \mathrm{m}$ particle size using a Retsch SM300 cutting mill. The first part of the sample to be passed through the mill was disposed of to reduce the risk of inclusion of contamination from mill surfaces. While there is also a possibility that contamination from abrasion of the steel cutting blades may have occurred, since the samples were all soft materials, this is considered low risk. The milled samples were digested in nitric acid $\left(\mathrm{HNO}_{3}>70 \%\right)$ according to the method set out in ENISO-16,968:2015. Duplicate aliquots were each prepared from $500 \mathrm{mg}$ of each sample and made up as an aqueous solution for analysis. A reagent blank sample and a sample using a standard reference material were also prepared. Each of these was analysed using Inductively Coupled Plasma Mass Spectroscopy (ICP-MS) to quantify the trace quantities of PTEs in accordance with EN-ISO-17294-1:2006. The instrument was externally calibrated using standard solutions (50 ppb, $1000 \mathrm{ppb}$ ). The ICP-MS spectral data were analysed using methods developed at The University of Leeds accounting for errors from matrix effects. Analysis results for mercury and chromium were not reliably quantified in this process so a subset of the samples were subsequently analysed in an external laboratory to determine levels of these elements.

\section{PAH Analysis}

PAH analysis was conducted by following a multi-step procedure: extraction; evaporation-concentration; determination. Materials for analysis were kept intact 'as received' as much as possible (without milling) to avoid loss of surface contaminants. The extraction step was carried out using an accelerated solvent extractor (ASE®) with the conditions as summarised in Table 4 and following a procedure adapted from the methodology as presented in reference [36]. The evaporation/concentration step was carried out using an automated evaporator (SP Scientific Genevac Rocket). This step removes the solvent (toluene) and concentrates the residue through heating $\left(40^{\circ} \mathrm{C}\right)$ and centrifuging $(1500 \mathrm{rpm})$ of the samples in evaporation flasks. 
Table 4 Accelerated solvent extraction conditions

\begin{tabular}{ll}
\hline System pressure & $11 \mathrm{MPa}$ \\
Oven temperature & $120{ }^{\circ} \mathrm{C}$ \\
Sample size & $10 \mathrm{~g}$ \\
Oven heat-up time & $5 \mathrm{~min}$ \\
Static time & $10 \mathrm{~min}$ \\
Static cycles & 2 \\
Rinse volume & $40 \mathrm{~mL}$ \\
Solvent & Toluene \\
Nitrogen purge & $300 \mathrm{~s}$ \\
Extraction time & $30 \mathrm{~min}$ \\
Cell size & $100 \mathrm{~mL}$ \\
\hline
\end{tabular}

PAH content in the processed samples was determined by measurement in accordance with standard methods [37] using a GC-MS instrument (Perkin Elmer Clarus 600C) coupled with SIM (Single Ion Monitoring) at $70 \mathrm{eV}$. The $\mathrm{GC}$ oven was set at $60{ }^{\circ} \mathrm{C}$ for $4 \mathrm{~min}$, then increased at $5{ }^{\circ} \mathrm{C} /$ min to $300{ }^{\circ} \mathrm{C}$, held for $10 \mathrm{~min}$, then cooled to $290{ }^{\circ} \mathrm{C}$. The GC injection port was heated at $300{ }^{\circ} \mathrm{C}$ and the transfer line from the $\mathrm{GC}$ to $\mathrm{MS}$ was heated at $290^{\circ} \mathrm{C}$. Target compounds were separated with a Perkin Elmer Elite $5 \mathrm{~ms} 5 \%$ phenylmethyl silicone column $30 \mathrm{~m} \times 0.25 \mathrm{~mm}$ with $1 \mu \mathrm{m}$ film thickness (J\&W Scientific Folsom). A sample volume of $1 \mu \mathrm{l}$ was injected for each sample at split-less mode by supplying helium as carrier gas at a constant column flow rate of $1.4 \mathrm{ml} / \mathrm{min}$. A deuterated internal standard (PAH Mix 31 ) and EPA 16 PAH calibration mixture (PAH Mix 25) were used for calibration [29].

\section{Results and Discussion}

\section{Measured Levels of PTE Contamination}

The measured levels of PTEs in the harvested road-verge biomass samples, the farm feedstocks and the digestate are presented in Table 5. The average concentrations of PTE in the road-verge biomass, the farm feedstocks and in the digestate are presented in Fig. 2 (on a log scale) for comparison.

There are a few individual samples of road-verge biomass which show levels of PTEs notably higher than other samples. For example, the concentrations of $\mathrm{Pb}$ and $\mathrm{Mn}$ at site one (S1) are statistically significantly higher than other samples and higher than the farm feedstocks. In general, the levels of PTEs in the road-verge biomass are broadly in line with the levels observed in the farm feedstock. While the comparison shows that average levels of arsenic and manganese are slightly elevated and that for lead is considerably higher, most of the measured values were commensurate with the background average levels in UK herbage (see Table 1). Sample S1/H1.1 was the only sample to show

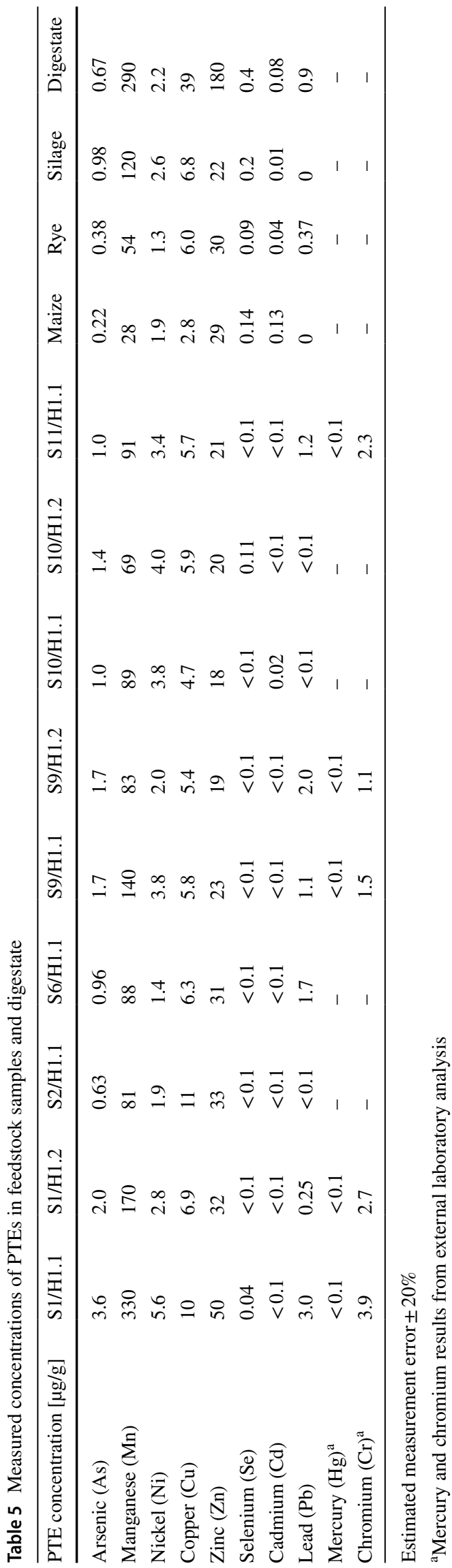


Fig. 2 Comparison of PTE concentrations in feedstocks and digestate (logarithmic scale)

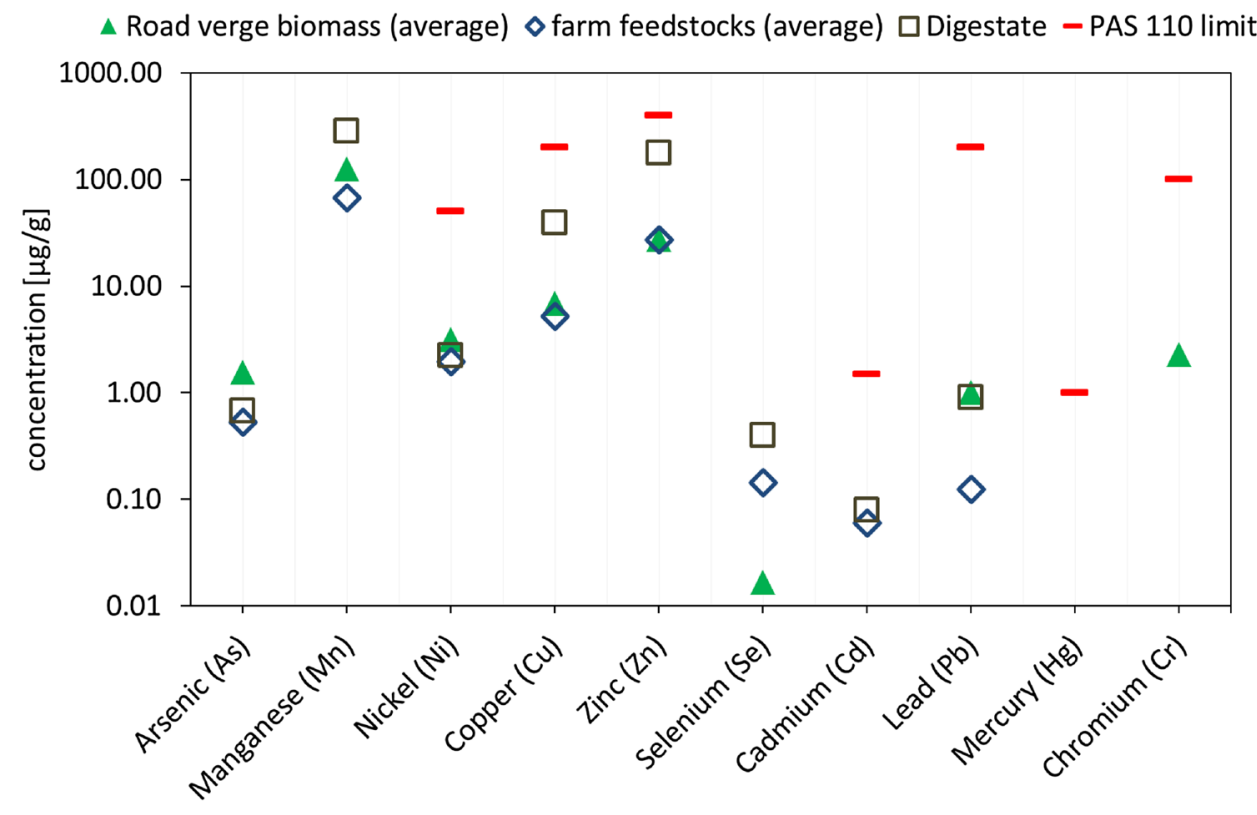

levels consistently higher than the average background. It is noted that a study of metals content of urban road-verge grass in Germany [38] reported levels of $\mathrm{Mn}, \mathrm{Zn}, \mathrm{Cu}, \mathrm{Pb}, \mathrm{Cr}$ and $\mathrm{Cd}$ which were all similar or, at least, in the same order of magnitude as those reported here.

In all cases for the farm feedstocks and in most cases for the road verge biomass, the levels of PTEs were similar or lower than in the output digestate. The levels in the digestate were well within the limits set out in PAS 110. It is noted that levels of $\mathrm{Mn}, \mathrm{Cu}, \mathrm{Zn}$ and $\mathrm{Se}$ in the digestate were increased by a higher proportion compared to the other PTEs. These elements are present in the additives used as AD stimulants. Other possible sources of some of these metals include contamination from wear of metal parts in the AD plant itself. AD stimulant additives were used at the Scrivelsby plant so it is likely that this is the main source of the increased levels in the digestate.

\section{Measured Levels of PAH Contamination}

The measured levels of 16-priority US EPA PAH as well as the total $\sum 16 \mathrm{PAH}$ in the harvested road-verge biomass samples, the farm feedstocks and the digestate are presented in Table 6. The average concentrations of PAH in the roadverge biomass, the farm feedstocks and in the digestate is presented in Fig. 3 (on a log scale) for comparison.

Sample S10/H1.1 showed the highest concentrations of benzo(a)pyrene (BaP) and $\sum 16 \mathrm{PAH}$ at 370 and $3400 \mu \mathrm{g} /$ $\mathrm{kg}$ respectively. These two PAH metrics are commonly used as markers for overall PAH contamination. These values are considerably higher than the mean levels reported in UK rural herbage which are 9 and $220 \mu \mathrm{g} / \mathrm{kg}$ for $\mathrm{BaP}$ and $\sum 16$ PAH respectively (see Table 2 ). This suggests that the pollution from road vehicles is indeed a significant contributor to the contamination of the verge. It is noted that normal background concentrations (NBCs) for BaP soil contamination in rural areas are advised as $500 \mu \mathrm{g} / \mathrm{kg}$ [39]. Despite contamination in many samples being above the expected levels for rural areas, all samples contained concentrations of benzo(a)pyrene and $\sum 16$ PAH below the recommended limits for agriculture soils (1.5 and $40 \mathrm{mg} / \mathrm{kg}$ respectively) [40].

PAH concentrations varied greatly between sites but they are comparable to other values reported in the literature for herbage [41].

While the traffic monitoring data (see Table 3) does not, in some cases, present the actual traffic flow at the precise location of the site, a qualitative analysis shows a crude correlation between proximity to main roads and $\mathrm{PAH}$ concentrations in samples. The sites in proximity to the higher traffic levels (S6 and S10) presented the highest PAH concentrations. Sites adjoining main roads with lower traffic levels (S1 and S2) presented lower contamination.

The farm feedstocks (maize, rye grass and grass silage) showed, on average, a lower degree of contamination by PAH than the road verge biomass. The maize sample did show a level of contamination in a similar order to the roadverge samples although this appears to be almost entirely owing to a very high concentration of indeno(1,2,3-cd)pyrene. The provenance of this contamination is not clear and the datum appears to be an outlier.

The digestate contained very low levels of PAH with just $4.8 \mu \mathrm{g} / \mathrm{kg}$ of benzo(k)fluoranthene detected and other PAHs indicated below the reliable measurement limit of the method. The implication of this observation is that the AD process may have either degraded the PAH compounds or they are partitioned away from the digestate in the process. If 


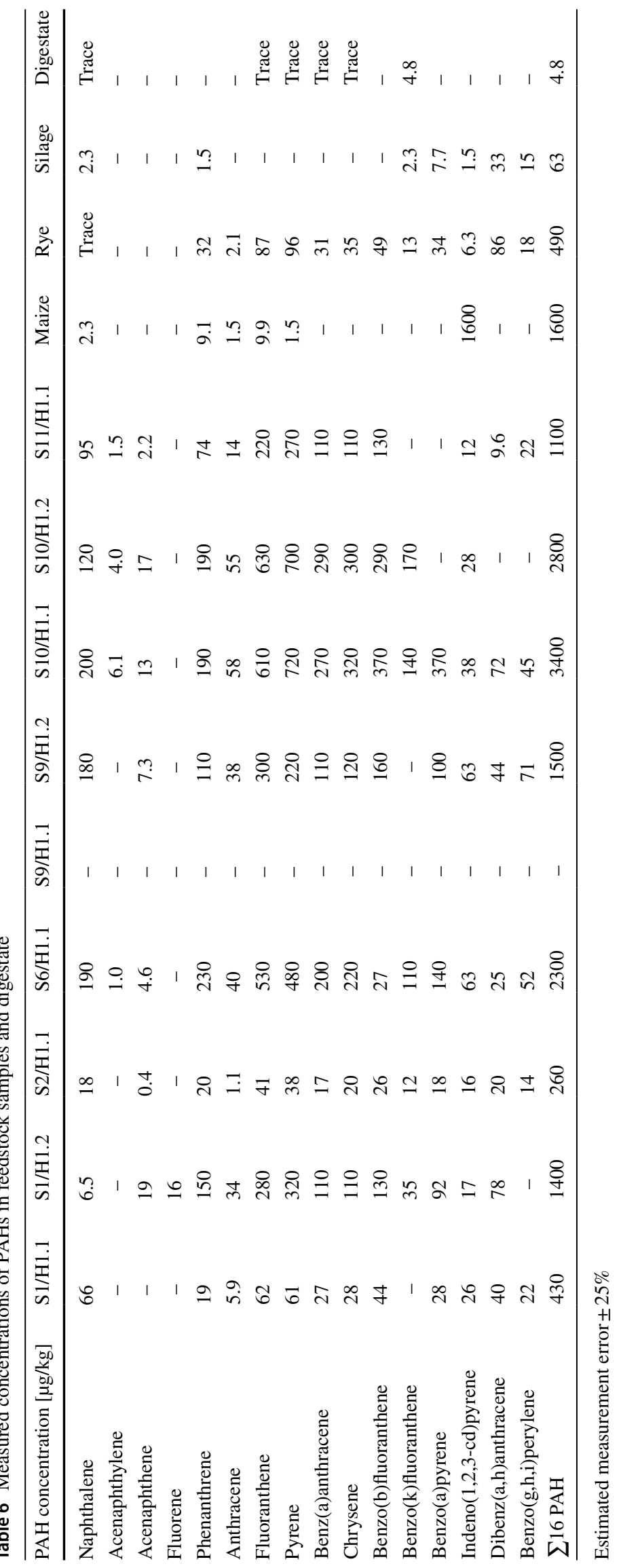


Fig. 3 Comparison of PAH concentrations in feedstocks and digestate (logarithmic scale)

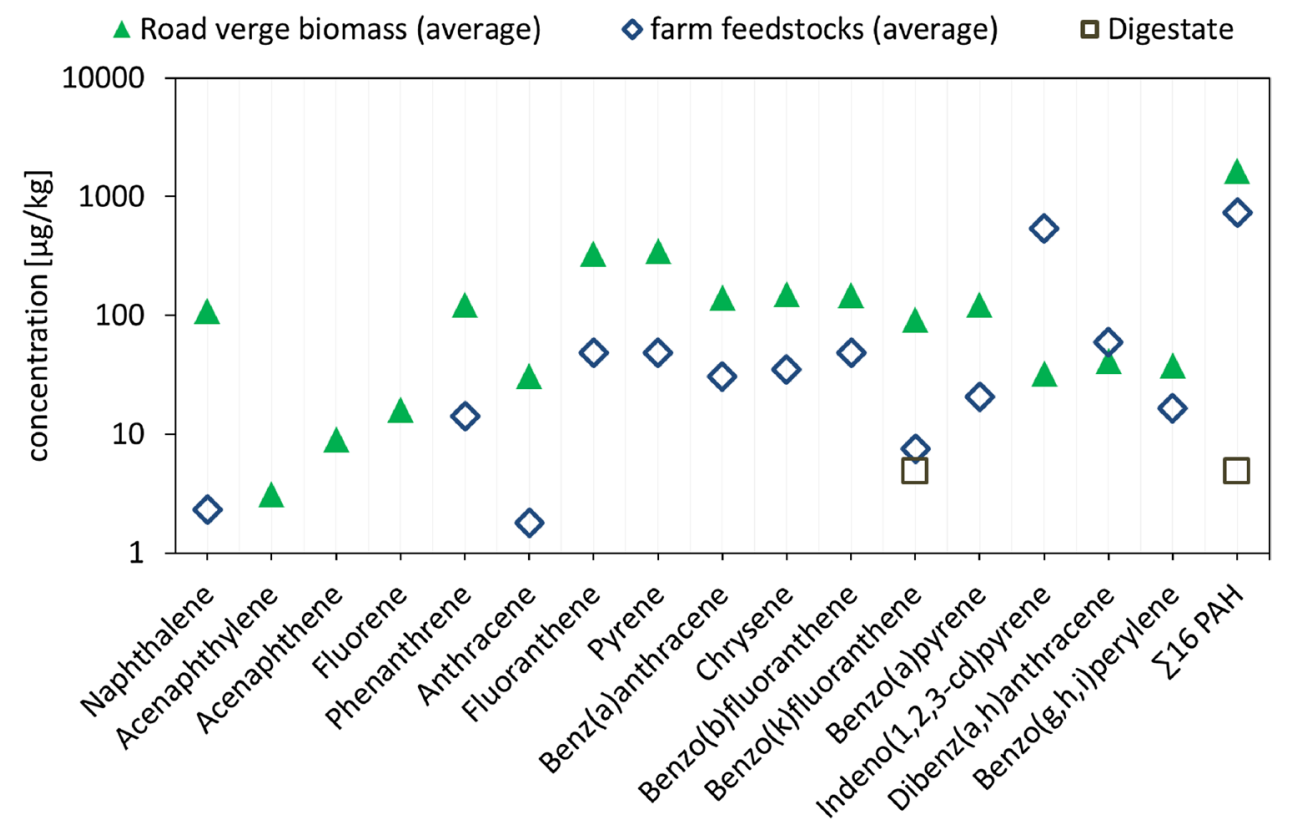

the former is the case, AD could be a useful means for PAH biodegradation to reduce contamination in soils. However, it is possible that the PAHs are mainly removed from the solid digestate as the liquid fraction is separated. A more detailed and focussed study would be useful to investigate this aspect of the process.

\section{Conclusions}

This study analysed a series of samples of road-verge biomass to assess the levels of contamination by both PTEs and PAHs. For comparison, three different farm-feedstocks used for $\mathrm{AD}$ were also analysed. The digestate from an AD plant using both the road-verge biomass and the farm-feedstocks was also analysed.

The results showed that the PTE levels in the road verge biomass are broadly comparable to the levels measured in the farm-feedstocks and also in-line with the background levels reported in UK rural areas. The AD digestate had some increased levels of contaminants compared to the feedstocks but this is likely due to the addition of zinc, copper, manganese and selenium, all of which are used in AD stimulant additives. In any case, the levels of all PTEs in the digestate were well within statutory limits for use of the material as agricultural fertilizer.

PAH contamination was observed to be somewhat higher in the road verge biomass compared to the farm feedstocks and higher than the expected background levels reported in UK rural areas. This is not unexpected since emissions from road vehicles is a known source of PAH pollution. Despite the noted contamination levels, the resulting digestate showed no significant contamination suggesting that the AD process either effectively degrades the PAH or the PAHs are partitioned in the AD process and separated from the solid digestate.

From this study, it is shown that known sources of PTE and PAH contamination from road traffic are not found in concentrations on road verge biomass at high enough levels to cause adverse effects or concerns for its safe use as an AD feedstock.

Acknowledgements The authors are grateful for funding from the EPSRC Centre for Doctoral Training in Bioenergy (Grant No. EP/L014912/1). We are also very grateful to Lincolnshire County Council for providing a financial contribution in part support of the project and for providing materials, data and networking without which the project would not have been possible. The authors acknowledge and thank Scrivelsby Farms for suppling samples of materials and assistance. Thanks also to Lincolnshire Wildlife Trust for providing support for the project. We acknowledge Judith Ford and Aaron Brown for their work in associated studies.

OpenAccess This article is distributed under the terms of the Creative Commons Attribution 4.0 International License (http://creativeco mmons.org/licenses/by/4.0/), which permits unrestricted use, distribution, and reproduction in any medium, provided you give appropriate credit to the original author(s) and the source, provide a link to the Creative Commons license, and indicate if changes were made.

\section{References}

1. Department of Environment Food and Rural Affairs, Anaerobic Digestion Strategy and Action Plan: A commitment to increasing energy from waste through Anaerobic Digestion, DEFRA, UK Government, UK, (2011)

2. Haltas, I., Suckling, J., Soutar, I., Druckman, A., Varga, L.: Anaerobic digestion: a prime solution for water, energy and food nexus challenges. Energy Procedia 123, 22-29 (2017) 
3. Pick, D., Dieterich, M., Heintschel, S.: Biogas production potential from economically usable green waste. Sustainability 4, 682 (2012)

4. Meyer, A.K.P., Ehimen, E.A., Holm-Nielsen, J.B.: Bioenergy production from roadside grass: a case study of the feasibility of using roadside grass for biogas production in Denmark. Resour. Conserv. Recy. 93, 124-133 (2014)

5. Piepenschneider, M., Bülhe, L., Hengsen, F., Wachendorf, M.: Energy recovery from grass of urban roadside verges by anaerobic digestion and combustion after pre-processing. Biomass Bioenerg. 85, 278-287 (2016)

6. Tambone, F., Scaglia, B., D’Imporzano, G., Schievano, A., Orzi, V., Salati, S., Adani, F.: Assessing amendment and fertilizing properties of digestates from anaerobic digestion through a comparative study with digested sludge and compost. Chemosphere 81, 577-583 (2010)

7. Koszel, M., Lorencowicz, E.: Agricultural use of biogas digestate as a replacement fertilizers. Agric. Agric. Sci. Procedia 7, 119-124 (2015)

8. Hanley, M.E., Wilkins, J.P.: On the verge? preferential use of roadfacing hedgerow margins by bumblebees in agro-ecosystems. J. Insect Conserv. 19, 67-74 (2015)

9. Scholes, P., Areikin, E. (eds.), A Survey of The UK Anaerobic Digestion industry in 2013, Waste Resources Action Programme WRAP, UK, (2014)

10. AD Map of UK: Anaerobic Digestion and Bioresources Association website, http://adbioresources.org/about-ad/ad-map (2018). Accessed October 2018

11. Department for Transport, Road Lengths in Great Britain: 2016, https://www.gov.uk/government/statistics/road-lengths-in-great -britain-2016, UK Government, UK, (2017). Accessed October 2018

12. Cheffins, N.: A Feasibility Study into the Utilisation of Anaerobic Digestion to Sustain the Harvesting of Low Input High Diversity Road Verge Biomass. Peakhill Associates, Lincoln (2015)

13. Brown, A., Ford, J., Bale, C., Cheffins, N., Mason, P.E., PriceAllison, A., Ross, A., Taylor, P.: The use of road-verge grass as a feedstock for farm-fed Anaerobic Digestion plants, article in preparation for publication (2019)

14. Nieboer, E., Richardson, D.H.S.: The replacement of the nondescript term 'heavy metals' by a biologically and chemically significant classification of metal ions. Environ. Pollut. Ser. B 1, 3-26 (1980)

15. Chen, Y., Cheng, J.J., Creamer, K.S.: Inhibition of anaerobic digestion process: a review. Bioresour. Technol. 99, 4044-4064 (2008)

16. Madejón, P., Murillo, J.M., Marañón, T., Cabrera, F., López, R.: Bioaccumulation of $\mathrm{As}, \mathrm{Cd}, \mathrm{Cu}, \mathrm{Fe}$ and $\mathrm{Pb}$ in wild grasses affected by the Aznalcóllar mine spill (SW Spain), Sci. Total Environ. 290, 105-120 (2002)

17. Northern Ireland Environment Agency, Anaerobic Digestate: Quality Protocol, NIEA, Belfast, pp. 26 (2014)

18. PAS 110: Specification for Whole Digestate, Separated Liquor and Separated Fibre Derived from the Anaerobic Digestion of Source-Segregated Biodegradable Materials. Waste Resources Action Programme, UK (2010)

19. Romero-Güiza, M.S., Vila, J., Mata-Alvarez, J., Chimenos, J.M., Astals, S.: The role of additives on anaerobic digestion: a review. Renew. Sustain. Energy Rev. 58, 1486-1499 (2016)

20. Thorpe, A., Harrison, R.M.: Sources and properties of nonexhaust particulate matter from road traffic: a review. Sci. Total Environ. 400, 270-282 (2008)

21. Pulles, T., Denier van der Gon H., Appelman, W., Verheul, M.: Emission factors for heavy metals from diesel and petrol used in European vehicles. Atmos. Environ. 61, 641-651 (2012)

22. Environment Agency, UKSHS Report No. 7: Environmental concentrations of heavy metals in UK soil and herbage, UK Government, UK: (2007)
23. Akbar, K.F., Hale, W.H.G., Headley, A., Athar, M.: Heavy metal contamination of roadside soils of Northern England. Soil Water Res. 1, 158-163 (2006)

24. Apeagyei, E., Bank, M.S., Spengler, J.D.: Distribution of heavy metals in road dust along an urban-rural gradient in Massachusetts. Atmos. Environ. 45, 2310-2323 (2011)

25. Boulter, P., A review of emission factors and models for road vehicle non-exhaust particulate matter, TRL report PPR065, DEFRA, UK: (2005)

26. Abdel-Shafy, H.I., Mansour, M.S.M.: A review on polycyclic aromatic hydrocarbons: Source, environmental impact, effect on human health and remediation. Egypt. J. Pet. 25, 107-123 (2016)

27. Bernal-Martinez, A., Patureau, D., Delgenès, J.P., Carrère, H.: Removal of polycyclic aromatic hydrocarbons (PAH) during anaerobic digestion with recirculation of ozonated digested sludge. J. Hazard. Mater. 162, 1145-1150 (2009)

28. Environment Agency, UKSHS Report No. 9: Environmental concentrations of polycyclic aromatic hydrocarbons in UK soil and herbage, UK: (2007)

29. USEPA.: Method TO-13A.: Determination of Polycyclic Aromatic Hydrocarbons (PAHs) in Ambient Air Using Gas Chromatography/Mass Spectrometry, Compendium of Methods for the Determination of Toxic Organic Compounds in Ambient Air. US Environmental Protection Agency, USA (1999)

30. VROM, Emissies van Metalen en PAK door Wegverkeer, in, Netherlands, 1997

31. Rogge, W.F., Hildemann, L.M., Mazurek, M.A., Cass, G.R., Simoneit, B.R.T.: Sources of fine organic aerosol. 3. Road dust, tire debris, and organometallic brake lining dust: roads as sources and sinks. Environ. Sci. Technol. 27, 1892-1904 (1993)

32. Wenborn, M.J., Coleman, P.J., Passant, N.R., Lymberidi, E., Sully, J., Weir, R.A.: Speciated PAH Inventory for the UK, DEFRA report, AEA Technology Environment, UK (1999)

33. Langenkamp, H., Part, P., Erhart, W., Pruess, A. (eds.), Organic Contaminants In Sewage Sludge for Agricultural Use, European Commission Joint Research Centre (2001)

34. Department for Transport, Traffic counts - Transport statistics, https://www.dft.gov.uk/traffic-counts/cp.php?la=Lincolnshire, UK Government, UK (2016). Accessed October 2018

35. W.R.A.P.: Operational A.D. Sites, http://www.wrap.org.uk/conte nt/operational-ad-sites, Waste Resources Action Programme, UK (2018). Accessed October 2018

36. Murphy, B., Lingam, S., Richter, B., Carlson, R., Simultaneous Extraction of PAHs and PCBs from Environmental Samples Using Accelerated Solvent Extraction, Thermo Fisher Scientific, Salt Lake (2012)

37. USEPA.: Methods for Organic Chemical Analysis of Municipal and Industrial Wastewater in: Method 610-Polynuclear Aromatic Hydrocarbons-Appendix A to Part 136. US Environmental Protection Agency, Washington (1984)

38. Piepenschneider, M., De Moor, S., Hensgen, F., Meers, E., Wachendorf, M.: Element concentrations in urban grass cuttings from roadside verges in the face of energy recovery. Environ. Sci. Pollut. Res. 22, 7808-7820 (2015)

39. TGS04 - Technical Guidance Sheet on normal levels of contaminants in English soils TGS04, Department of Environment Food and Rural Affairs, UK Government, UK (2012)

40. Environment Agency.: Review of the fate and transport of selected contaminants in the soil environment, UK Government, UK (2003)

41. Wild, S.R., Jones, K.C., Johnston, A.E.: The polynuclear aromatic hydrocarbon (PAH) content of herbage from a long-term grassland experiment. Atmos. Environ. A 26, 1299-1307 (1992)

Publisher's Note Springer Nature remains neutral with regard to jurisdictional claims in published maps and institutional affiliations. 